\title{
Interactive Panorama VR360 for Corporate Communications: An Industrial Scenario Case Study
}

\author{
Zi Siang See ${ }^{1 *}$, Mohd Shahrizal Sunar ${ }^{1}$, Agus Kusnayat ${ }^{2}$, Kamarulzaman Ab \\ Aziz $^{3}$
}

${ }^{1}$ School of Computing, Faculty of Engineering, Universiti Teknologi Malaysia, 81310 Johor Bahru, Johor, Malaysia.

${ }^{2}$ School of Industrial Engineering, Telkom University, 40257 Bandung, West Java, Indonesia.

${ }^{3}$ Faculty of Management Multimedia University, Malaysia.

Received 28 June 2018; accepted 5 August 2018, available online 24 August 2018

\begin{abstract}
This case study explores interactive panorama implementation for corporate communications virtual reality 360 (VR360) application. Interactive panorama permits spherical panorama digital imagery being presented in three hundred sixty degrees visual experience instead of single angle limitation in conventional static image. The study proposes the use of interactive panorama as a corporate communications tool being considered from three experimental PEP aspects. The exploration of PEP framework seeks the suitability of implementing three key aspects of people, equipment and product for interactive panorama virtual reality 360 experience. With the developing advances of interactive panorama, it has been introduced by online social media providers as essential feature which allows individual and corporate users to post 360 content. This case study takes advantage on the actual on-going marketing experience and technical insight of a participating case company and several industrial scenario use cases. In this paper we describe interactive panorama content creation, PEP framework, a user study and directions for future work.
\end{abstract}

Keywords: Corporate Communications; Interactive Panorama; Spherical Panorama; Virtual Reality 360

\section{Introduction}

Image has been one of the most used reproduction medium for recording and presenting location-based subjects especially for architectural and cultural heritage context. National Geographic photographer Nichols [4] explains how the business of conventional print publication turns into selling Apps on mobile platform, digital publication can provide greater possibility of creative presentation and it can widely provide ondemand content access for internet-enabled users. One of the major limitations of conventional photography technique is that it is confined with the optical lens angle on single perspective only. A mobile app-based publication called the "50 Places" was introduced by National Geographic Traveller [4], one of the key features in this electronic publication is a built-in "See a $360^{\circ}$ view of Jerusalem's Old City” interactive panorama navigation. Merriam-Webster's dictionary has stated the term panorama is the combination of the Greek's " $\pi \tilde{\alpha} v$ " and "ó $\rho \alpha \mu \alpha$ " that carries the meaning of "all" and "sight", it has been explained about the idea being expressed during the early 19 centuries of a panorama painter's goal was to reproduce the real world so realistically that the onlookers could believe that what they were seeing was real [7]. Spherical panorama image reproduction [1], [2], [3], [8], [11] can be used for interactive panorama image projection on suitable digital platforms, which is also commonly known as virtual reality 360 (VR360) experience. Recent development in digital media industries has allowed interactive panorama feature being made available for major social media, online video channel and corporate webpages and mobile applications. Interactive panorama permits the users the possibility to interactively navigate the processed image of a locationbased scene at three hundred sixty degrees ideally without any perspective limitation on a displayable digital platform such as on any web based computer browser and mobile devices. Fig. 1 is an illustration of basic concept process of the content-creation, multirow configuration (multiple angles) for spherical panorama image reproduction and interactive panorama user experience. 


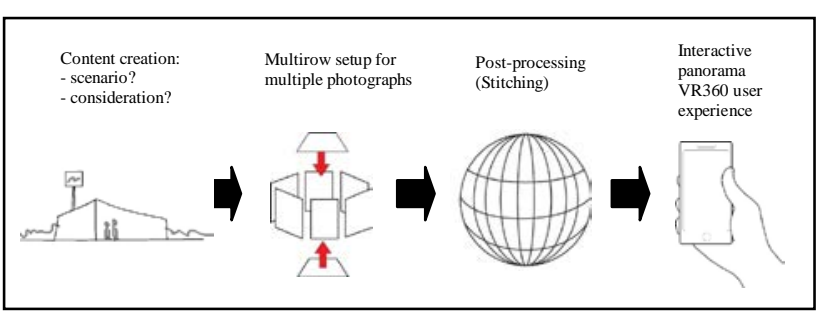

Fig. 1: Interactive panorama research-creation.

The multirow method of spherical panorama image reproduction for interactive panorama presentation usually involves more than one effective photograph image to be recorded for combining into the complete 360 degree view [8], [11]. The approach of interactive panorama presentation can be seen in the "street view" of Google Map and "street side” of Microsoft Bing Map. It is observed that the interactive panorama features from Google Map and Microsoft Bing Map may have suffered from certain identifiable visual abnormality, these include the parallax error or ghosting effect resulted by fast moving objects recorded in the multiple photographs during the spherical panorama image reproduction process. The example of visual abnormality can be visible in Fig. 2(a) and 2(b), parallax error is an undesirable result from misalignment of photographic angles during the multiple photographs stitching process. Interactive panorama as an innovative solution for imaging usage however may be less mature if the current work in the creative industry exhibit certain level of technical issues or compromised content accuracy. The interactive panorama as a proposed communications tool in such immature condition may face difficulties when being marketed. Hence, the corporate users who are interested to incorporate interactive panorama in their marketing materials, may doubt the reliability and the usage of interactive panorama. The technology acceptance can be another issue for corporate users to set corporate communications budget and funding for investing into the interactive panorama implementation.

(a) (b)

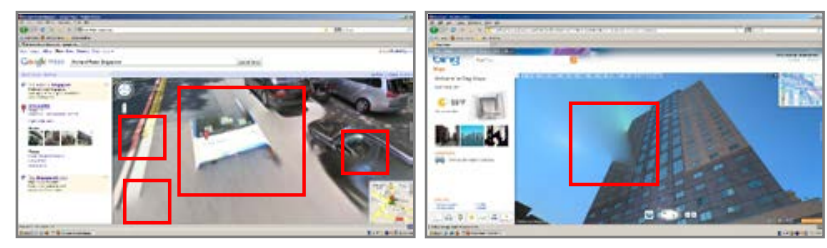

Fig. 2: VR360 image errors in some public use cases.

The reliability and the marketing interest of using interactive panorama for corporate communications has not been always cleared for both corporate organization and content producers. The main contribution of this study focuses on the case study implementation of interactive panorama considered from the proposed PEP framework consist of three aspects of people, equipment and products for corporation communications use cases.
The industrial scenario case study in this paper takes advantage on a case company Reina Imaging from Reina group of companies in Malaysia to exploring several selected example use cases for interactive panorama implementation.

The initial development of the PEP framework will be discussed from the perspective of use cases that may have different business characteristics from various industries. The case clienteles are selected from the range of food and beverage industry, automobile industry, hotel and retail sectors. The findings of this exploration can be treated as a marketing reference for interactive panorama users and providers such as corporate users, creative advertising agencies, photography production studios and software developers are who are interested in interactive panorama VR360 for the use of corporate communication context.

\section{Background}

\subsection{Image and Corporate Communications}

Corporate identity often can be visual, and it is being communicated two ways towards both the internal and external [5] audiences, hence, tablet computers and mobile devices have becoming a handy medium for presenting corporate related information. Corporations commonly utilize the potential of organizations' websites that support those organizations' efforts to communicate public relationship and to demonstrate corporate social responsibility [13], the interactive content featured in the website or mobile-internet media often can be presented to the internal or public users anywhere and anytime provided the convenient of internet connectivity is mandatory. Corporate online components including company blogs, RSS feeds, streaming video, podcasts, image photographs, and downloadable documents such as fact sheets [21] are some form of distribution being presented to the public literally shaping the public perception towards the specific corporation. One important objective of corporations on the website or online context is to promote effective communications with consumers as the web atmospheric cue is comparable to a brick-and-mortar cue and this has been described as "any web interface component within an individual's perceptual field that stimulates one's senses" [25]. It implies that web atmospheric might influence the online spending behavior of customer more than the physical product itself. A study has reported that offline store impressions were used as references for their online store counterparts [30], many consumers use both traditional physical store and virtual storefronts when engaging in spending behavior. However, for certain types of business nature, it is not easy to expect a virtual storefront has the capability of presenting similar quality of its physical store representation. The approach of using interactive panorama instead of conventional static imagery could be a potential attempt to suggest improvement for widening the online visual 
instructiveness and enhancing virtual experience that mimics the physical location of the store in real-world.

Corporate image in any form of visualization via variety of communications approaches for image building purposes can lead to a person's beliefs about an organization, formed by a multidimensional construct [23]. In terms of technological aspect, image is one of the core elements of multimedia and has been commonly used for corporate communications by organizations. On the other hand, interactive panorama in digital form of user navigated three hundred sixty degrees' imagery content of a location based subject [8], [11], [28] to be used in corporate digital media requires a higher complexity of implementation process as comparing to the use of conventional static digital image content. To illustrate, it is easy to insert static image content in a corporate PowerPoint presentation, however it requires a higher complexity of process for preparing an interactive panorama VR360 content and inserting it into a PowerPoint setup. In an explanation about Technology Acceptance Model (TAM), it was suggested that there are certain factors that will influence the users' considerations whether they will easily accept a new technology being presented, these include the user's perception about the degree of usefulness that is believed to be increasing his or her work performance and the ease of usage degree towards the new technology [22].

\subsection{The Solution Used by Case Company}

The availability of interactive art has become common as a result of the many ways in which the computer and the internet have facilitated it [10]. Interactive panorama digital projection requires working with the reproduction process that involve the multishot or multi-row configuration [2], [3], [8], [11], [16]. This process usually acquires and combines multiple angle images into a spherical panorama reproduction. For this study based on the technical requirements of the use cases, Nikon manufactured D3x camera is used for the preparation of interactive panorama imaging workflow in the case company Reina Imaging. The D3x is a photo recording instrument that can deliver 24.5 megapixels of full-frame photographic details, this allows the spherical panorama image rendering to be presented in a large resolution setting. The setup is equipped with Nikkor $16 \mathrm{~mm}$ f2.8 full-frame fisheye lens, and the construction of three hundred sixty degrees spherical panorama imagery is based on the combination of multiple photographic fish eye angles. Subject to different cases, high dynamic range image (HDRI) technical has also been included in interactive panorama content creation workflow. Manfrotto 303SPH Spherical Panorama Head is mounted Manfrotto 550Pro tripod for having multiple angle of images being acquired as shown in fig. 3. Post processing is arranged using digital image processer PTGui Pro and Autodesk Stitcher. Fig. 4 illustrates an example of the basic controllers provided in the digital navigation of interactive panorama content, it is compatible with computer displays, mobile devices, and VR head-mount-devices (HMD).

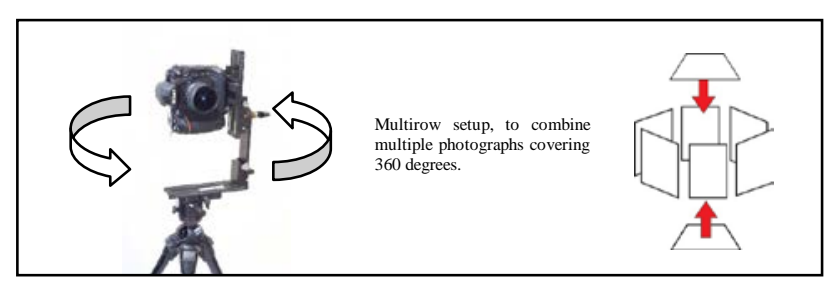

Fig. 3: Multirow setup with 360 capturing instrument.

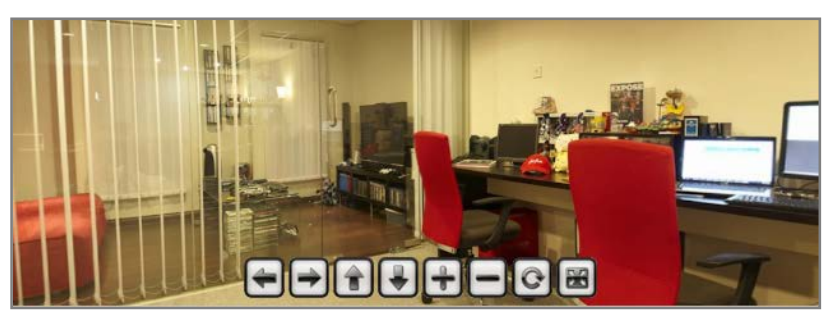

Fig. 4: Basic controllers for digital navigation in VR360.

\section{Case Study: People, Equipment, Product}

Case study methodology usage can be traced back in the early 1900s when it was popularly used by the University of Chicago, Department of Socialogy [34]. Case study can be done by giving special attention to completeness in observation, reconstruction and analysis of the cases under study [29]. A case study is a research strategy used when attempting to understand complex organization problems; in essence allowing one to focus on something which is sufficiently manageable and can be understood in all its complexity [19]. Yin [33] also highlighted that the reasons of conducting case studies includes explaining the linkages between causes and effects, to describe a phenomenon in its own context, to explore an issue or a question, etc. Triangulation for this study is achieved via methodological triangulation where multiple sources of data are used. This is done via the usage of several common types of case study sources of evidence as recognized by Stake [26] and Yin [33], namely, documents, archival records, interviews, direct observation and participant observation.

The framework of People, Equipment and Product (PEP) was initially developed from literature reviews and being refined from the process of informal and unstructured interviews conducted with the producers of the participating case company Reina Imaging. Marketing insights and opinions have formed to create the subjective relationship of people, equipment and product elements from the corporate communications development perspective towards marketing products or services being provided by the clienteles. Fig 5 illustrates a proposed theoretical framework of People, Equipment and Product (PEP). The interactive panorama being implemented in the context of corporate communications and corporate subjects will be explored from the perception of PEP framework, as a preliminary review and discussion. The aspects from PEP framework can be viewed as key interests from the perspective of corporate communications towards an organizational operation or a business. 


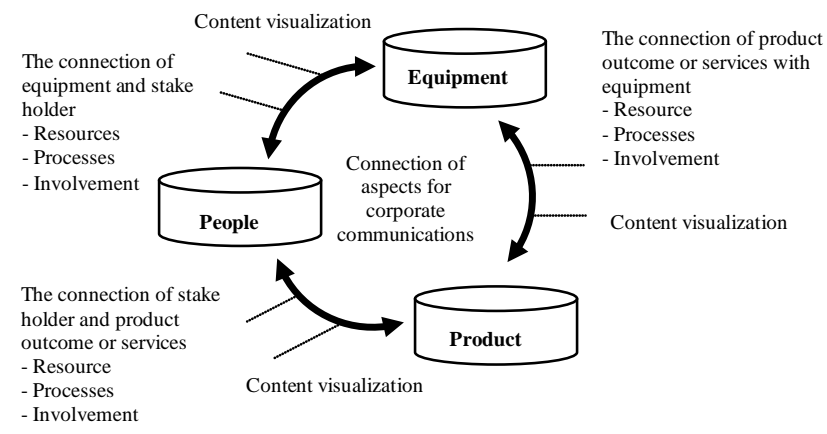

Fig. 5: Proposed framework PEP.

As a common understanding agreed by technical experts from the participating case company, people is a key element in every business, in various aspects. The visualization of images for a corporation can work together to form the corporation's reputation being communicated among a range of stakeholders, such as employees, customers, suppliers and investors [5]. To explore the people element as a concrete component in the corporate or business activities, the nature of human elements for each different corporation has to be identified. For example, the work nature of employees working in a restaurant entity has dissimilar sense of approach comparing to employees who work in an automobile showroom. It was being suggested that by recognizing the element of stakeholders within a corporation that includes the synergistic role that employees can take part in the overall positioning of corporate communications, significant achievements then can be accomplished such as satisfying corporate strategic objectives and generating sustainable competitive advantage [9]. The perception projected can be clearer if the people element of a corporation can be presented in the form of imagery comparing to textual form. Variety of media programs that involve employee communications can be one of the major contributions towards the practical public relations function of a corporation [31]. Conventionally, these media programs can include but not limited to corporate newsletter, corporate social responsibilities public booklet and real people being featured in successful story editorials.

Equipment is another vital aspect in almost every corporation. The term equipment is not limited to a mechanical tool such as a computer in an office or an electric oven in a kitchen. Restaurant environment can be considered as the core equipment for food and beverage industry. A well designed cabin space in a passenger aircraft carrier is core equipment for the airline company. From the perspective of lean thinking [32], managing the equipment element in any relevant form to ensure having desirable business productivity is a top interest in almost every product-based or service-based company. The technical location environment for a manufacturer plant with a combination of numerous machineries setup can be considered as equipment element for manufacturing industry. During the 2003 space shuttle Columbia disaster, it was reported by the Columbia Accident Investigation Board stated that there were many PowerPoint presentations by NASA brought to the board but the slide presentations with bullet-outline was somehow insufficient to provide clear and focused understanding communications towards the technical assessment of the investigation [15]. It was also being suggested that such assessment process during a technical investigation may require new types of media and new forms of knowledge visualization medium towards the equipment and location-based technical subject.

Product from a corporation usually is an outcome of people innovating with equipment. Product of a business or non-business organization can be referred as a physical product introduced by the corporation or service being provided by the corporation. Characteristic of a product from a corporation differs from one and another, and may evolve by time subject to the market requirement. For some businesses depending on the nature of the corporation, the product can be a location-based subject. A study has suggested that intraurban retail area patronage decisions are highly influenced by the image and impression of the area [6], where visual amenity is likelihood to impact the commercial success of the retail business. An empty space for rental in retail mall can be considered as their product that generates income from the monthly tenancy rental. A flight service would be possible only with the cabin crews servicing the flight passengers in the cabin space of an aircraft that is operated by an airline corporation. A study about consumer perceptions on web advertisements and motivation factors to purchase via the online shopping has stated that it may be appropriate to mix entertainment components with product information and also to implement creative web interface designs for more effective browsing [14], this may help the consumers with low levels of trust towards online corporate content and improve their involvement in online shopping or purchasing experience. An example of online purchasing experience can be an activity of online hotel booking by having evaluation from the visual amenity of the products or services being acquired. Various physical features for retail businesses that provide various services or enhanced retail atmosphere are technically unavailable in the online context, these intangibles elements perhaps can be available only to a limited extend during an online retail customer experience. Hence, interactive panorama being utilized for presenting an online shopping context or corporate location content may intend to improve digital user experience of online consumers towards virtual impression of the target business or corporation. A travel destination of a location-based subject can form from destination image and impression [17], any information that contributes to form the perception of the location-based subject may influence the belief towards a product preference. Having location-based subject as the product element of an organization, the destination image for a consumer towards a tourist location, hotel or retail mall can be constructed via multiple attributes including personal experience, knowledge-based input or visual 
amenities being offered via online channel. Visual content presented in online channel including website and mobile applications are part of the possible marketing implementation for communicating visual information of the location-based corporate entities towards public audience.

\section{Use Cases}

In the creation process of this study, several use cases of interactive panorama based on real clientele of case company were produced with the aspects of people, equipment and product (PEP). These aspects have been tested if they would fit into the scenario of clientele projects. These include clientele from food and beverage (F\&B) industries, retail and hotel and automotive industries.

For this study, the identity of case clienteles collaborated with case company has been disguised for non-disclosure business information protection. Subjective experience was being observed in a user study in heading 5 for suitability of PEP being adapted during the content-creation of interactive panorama with virtual reality 360 user experience. Subject to the corporate imaging requirements set by different case clienteles, some projects require digital imaging manipulation for commercial purposes, meanwhile some requires non-bias imagery content either for internal or external corporate communications usage. Fig. 6 shows a post-processing process of spherical panorama in producing 360 content for use cases projects.

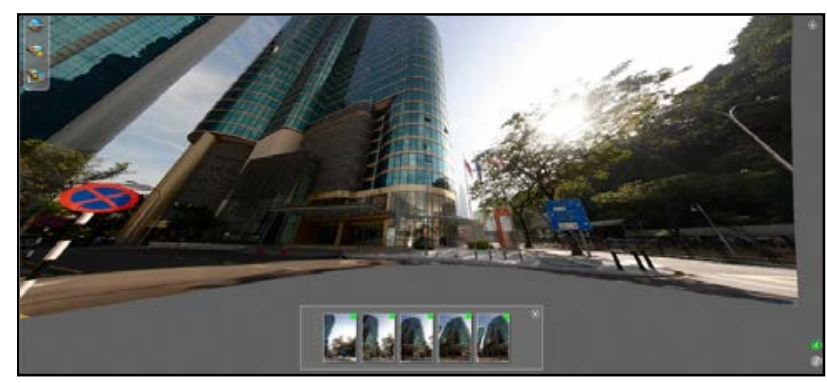

Fig. 6: Processing for combining multiple photographs.

\subsection{Food and Beverage Industries}

Food and beverage (F\&B) industries was found to have variety of content to be suitable for adaption in interactive panorama. Featuring new look of restaurant interior and exterior amenities is one of the useful activities of online corporate communications initiatives. Corporate communications is one of the active components by F\&B industries, it usually involves regular internal and external publishing materials about people stories and corporate social responsibility. For implementing virtual reality 360 experience, such example can be the interactive panorama of restaurant dining hall environment filled with guest with day mode or night mode, as some restaurant is operated throughout twenty-four hours daily. Another example can be an interactive panorama of restaurant space interior design complied with the official corporate identity, being used as a standard internal corporate identity guideline for new store design. Due to the nature of F\&B business, the food and beverage products are found to be technically irrelevant to the interactive panorama representation. Fig. 7 is an image rendering of spherical panorama imagery constructed from multiple photographs covering a complete three hundred sixty degrees for forming the interactive panorama projection of an F\&B restaurant entity. Interactive panorama digital projection has been configured for website and HTML5 output. This interactive panorama example that provides virtual reality 360 experience is made compatible with desktop-based and mobile platforms.
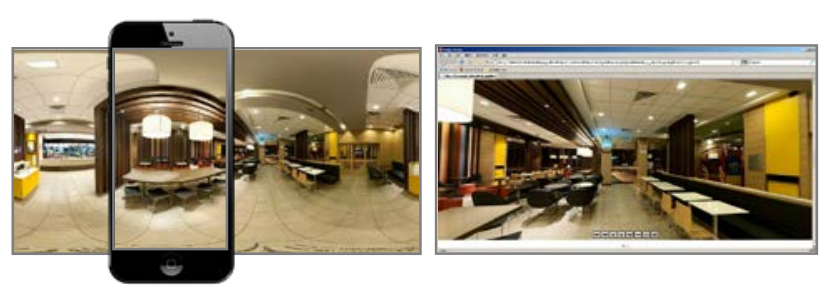

Fig. 7: VR360 on mobile and desktop displays.

\subsection{Retail and Hotel}

Retail and hotel management could take a benefit of interactive panorama for VR360 experience. According to the case company, the interactive panorama could be closely relevant to the aspects of people, equipment and product elements for business nature of retail and hotel operations. The conventional static corporate photograph image acquired from a fixed perspective may be narrowed to a selective angle of the location, it would be difficult to demonstrate actual location surrounding visual information in imagery content. Hence, interactive panorama is capable to allow visualization for all of the environment content by displaying the actual location of its genuine condition during the time it was photographically documented. Fig. 8 is an interactive panorama of the hotel ballroom. In this example, the space being shown in the hotel facility appears to be empty. In a possible ideal situation, an interactive panorama of a hotel lobby with pleasant environment filled with the guest and hotel officers can be included in the 360 visualized content. Fig. 9 is an actual interactive panorama projection in mobile platform of a retail mall facility, the content is being simulated and demonstrated in mobile platform showing the freedom of visual navigation.

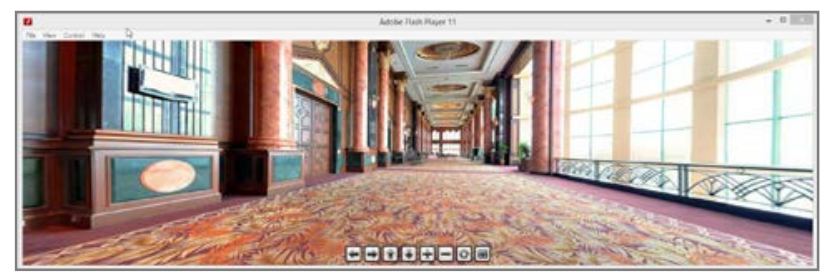

Fig. 8: VR360 on HTM5-compatible output. 

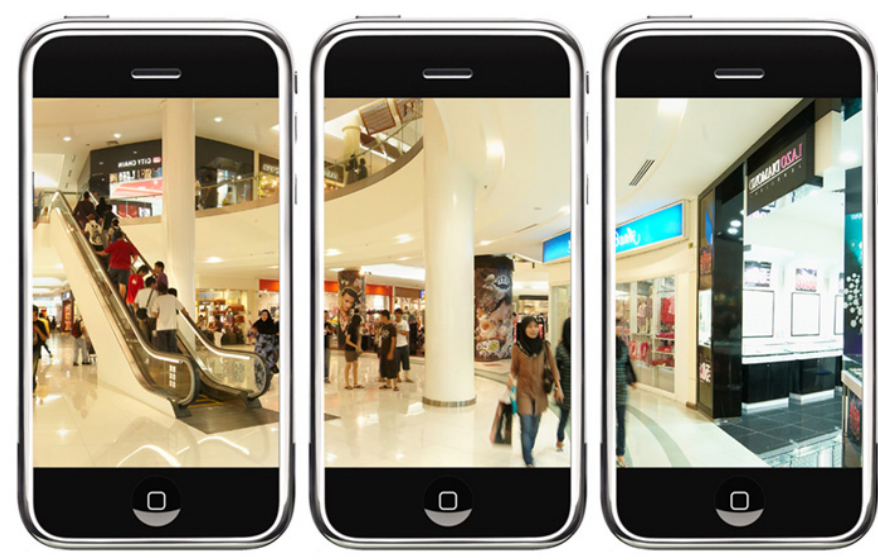

Fig. 9: Interactive panorama of retail facilities on mobile.

\subsection{Automotive Industries}

Automotive industries have products which can range from small cars specialization to luxury range of automobile design. From the advertising and corporate communications perspective, the capability of informing the target users can be essential to shape the public perception of the corporation. Fig. 10 illustrates an example of interactive panorama mainly feature the products of the automotive corporation. In concept, interactive panorama presentation can also suitable for featuring the image reproduction of interior for automotive design. Such VR360 usage is also applicable for institutional or corporate facilities for featuring demo studios, exhibition halls, showrooms and galleries.

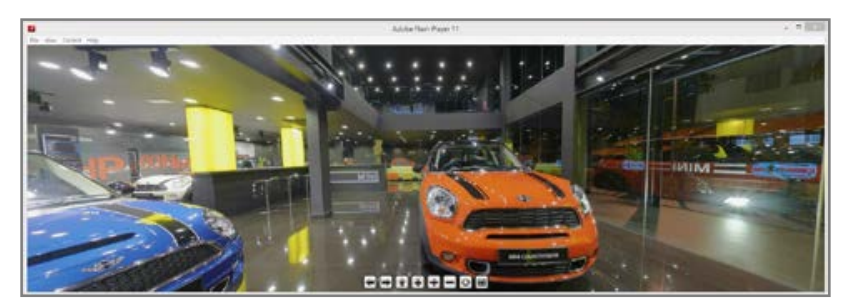

Fig. 10: Interactive panorama of commercial facilities.

\section{User Study}

To obtain a pilot study feedback from the users, we conducted a user study survey on interactive panorama. Our goal is to gauge user's experience of interactive panorama VR360 on several aspects. In the test, we examined user's impression on the digital navigation of interactive panoramas, and user's responses towards the element of people, equipment and products for interactive panoramas. Our study involved 52 participants between the ages of 18 to 36 . All selected users are inexperience in interactive panorama, the criteria of the selection was that users are new to the experience of interactive panorama and has no professional experience related to the subject matters. Users were being introduced to five different sets of interactive panorama and the fifth set contains an additional a walk-through experience where users are allowed to access several sub-locations within the main set which was a commercial paint manufacturer showroom. Pre-produced interactive panorama content was obtained from the use cases which involves the visual elements with aspects of people, equipment and products (PEP) during the content-creation and reproduction stage. All test was being simultaneously delivered in both a computer displays along with a 5.8 inches mobile display.

An average of $82 \%$ of the users agreed on interactive panorama image provides more visual-informative value compared to the normal static image, 30.2\% users responded that they strongly agree and being certain on this key aspect. An average of $77.7 \%$ responded that interactive panorama image content on an internetenabled personal computer web-based environment is very intuitive to navigate. In contrary, there is no significant different as compared to an average of $76.2 \%$ for mobile devices. An average of $82 \%$ of users felt guidance given in the interactive panorama content would be useful. Some users explained that they may be uncertain of what they should do for the first time, however it was reasonably easy to view the 360 images once they are familiar with the personal computer and mobile device internet-based platforms.

A set of questions were provided to gauge user's perception towards interactive panorama featuring the aspects of people, equipment and product (PEP). This was done by collecting feedback in response to the questions shown in Table 1 from 52 users. Answers were captured on a Likert scale of 1 to 7 , where 1 was "strongly disagree" and 7 "strongly agree". Fig. 11 illustrates all the responses and user study results. An average of $76.2 \%$ users agree of the people element being suitable for interactive panorama and about $78 \%$ for equipment element. An average of $83.2 \%$ of users feel interactive panorama is suitable to be associated for product element and 33.3\% users were certain of this consideration. Fig. 11, 12 and 13 demonstrates the details of the responses. The average results of these questions is illustrated in Fig. 14 in the Likert scale of 1 to 7.

Table 1: Questions about User's Perception towards PEP.

\begin{tabular}{cl}
\hline Questions & \multicolumn{1}{c}{ Descriptions } \\
\hline Q1 & "people element” is suitable to be captured \\
& or featured in an interactive panorama \\
& image representation (for example a hotel \\
& lobby with customers and officers).
\end{tabular}

Q2 “equipment element” is suitable to be captured or featured in an interactive panorama image representation (for example a kitchen as an "equipment” of the food and beverage industries).

Q3 “product element” is suitable to be captured or featured in an interactive panorama image representation (for example shops and space in a shopping mall as a "product" of a retail business). 


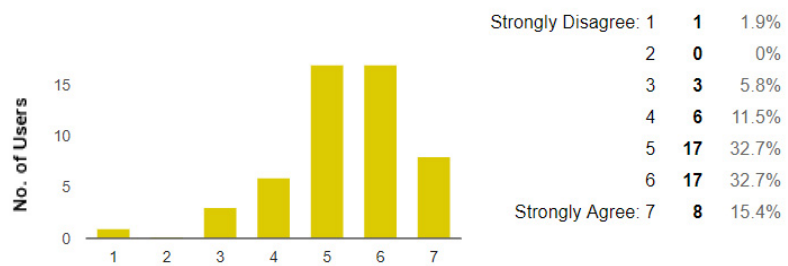

Fig. 11: Responses of Q1.

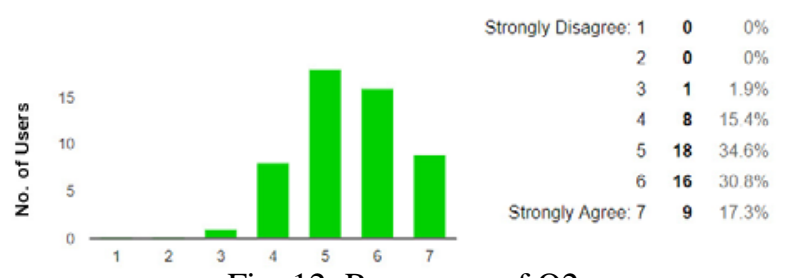

Fig. 12: Responses of Q2.
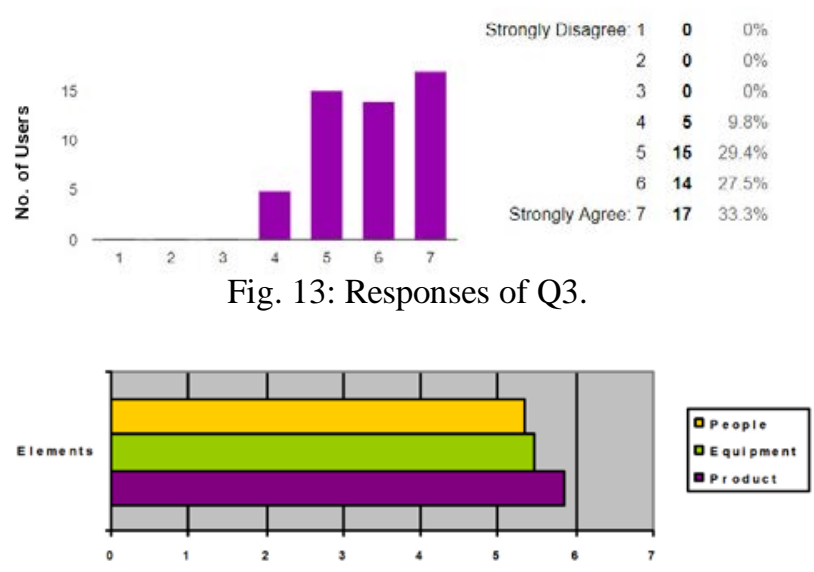

Fig. 14: Average results of the study in PEP aspects.

Some users found it useful for having clickable navigation buttons such as a viewing left, right, up and down icons to assist the viewing experience, however some users found that having buttons for navigating a 360 image viewing experience is redundancy as this can be done by dragging the panorama images for viewing directions, and mobile-devices usually can allow panning to different viewing directions because of the gyroscope feature. In addition, some users commented that "rollover voice navigation will enhance the system", and "It would be nice if it is not just a panorama image, but an interactive video in 360 modes". A small number of users expressed having a basic guidance of using interactive panorama may be provided, such as "navigation arrows is not obvious, I prefer a more attractive navigation arrows”, and "not so sure how to interactive with the 360 content at the beginning".

\section{Discussion}

In this paper, the industrial scenario case study has been arranged based on the observation of the case company Reina Imaging of Reina group of companies and some use cases selected. The case clienteles are some corporations having technical collaboration with Reina during the period of 2013-2017. The selected case clienteles in the study are mainly multinational and have physical entities geographically based in Malaysia or Singapore. The scope of data collection is arranged to the extent of using the proposed PEP framework towards the selected case clienteles and the characteristic of data collection has to be relevant to the corporate communications development of the case clienteles.

Interactive panorama, informally, is also known as virtual reality 360 (VR360). Interactive panorama that digitally works with spherical panorama image reproduction is a continuous development and innovation from the technical and marketing perspective. The advantage of panoramic vision has benefited project requirements for recording and presenting location-based imageries useful for various industries, such application can be seen in the example in the recent use of multi-shot panoramas that has the 360 camera configuration on Mars Rover Curiosity delivering panoramic images during space exploration operation [24]. Another example of interactive panorama implementation can be seen at the official web domain of a heritage structural Schloss Drachenburg in Germany that allows web visitors to view virtual tours in the form of interactive panorama projected from spherical panorama image reproduction. It provides digital interactive accessibility for the web users to view some of the architectural sites in interactive panorama, some of these locations are usually inconvenient for opening to the public due to safety and cultural heritage preservation concern. Discover Hongkong720 phone and tabled App is another practical use case launched by the Hong Kong Tourism Board [12] enabling guest from all around the world to preview travel destinations in 360 via mobile devices. This appears to be part of the corporate communications initiatives of the Hong Kong Tourism Board for supporting the tourism industry by providing interactive panorama imageries of the actual locations.

\section{Implications}

The study explores the implementation of interactive panorama imaging for corporate communications usage. It has been empirically observed that role of interactive panorama can be identified via PEP framework towards the possibility of how interactive panorama can be marketed and utilized from the corporate communications requirements of the case clienteles in this study. Interactive panorama implementation for digital media distribution can include digital form of usage in corporate websites, mobile applications, business presentations, technical briefings and training designs. Interactive panorama provides extended amount of imagery information for a corporation's presentation, however it is greatly dependent on the digital form of distribution and the internet connection availability. Spherical panorama reproduction for interactive panorama digital projection is usually constructed from multirow photographic process which involves combining multiple angle photograph images, this implies that the level of handling difficulties and reproduction cost can be comparatively higher comparing to the conventional static photographic image techniques. 
This study is part of the on-going research in the innovation of high fidelity VR360 solution. In future study, further optimization for the process of producing spherical panorama can be innovated to achieve higher representation accuracy of the real-world scene, having reduced cost and time of reproduction. With reduced cost and time for the reproduction of interactive panorama operation, VR360 solution may provide higher acceptance opportunities for usage of corporate communications. The framework of PEP can be one of the explorative approaches to market various new products and services, either from the perspective of business-to-business (B2B) or business-to-consumer (B2C) studies. Future work may suggest exploring PEP framework being potentially implemented into other types of product, solution and service-based innovations.

\section{References}

[1] Kent, B.R. Spherical Panoramas for Astrophysical Data Visualization. The Astronomical Society of the Pacific, (2017).

[2] Koeva, M. Luleva, M. and Maldjanski, P. Integrating Spherical Panoramas and Maps for Visualization of Cultural Heritage Objects Using Virtual Reality Technology. Sensors, (2017).

[3] Jung, J. Lee, J. Kim, B. and Lee, S. Upright adjustment of 360 spherical panoramas. Virtual Reality 2017, IEEE, (2017).

[4] Nichols, M. National Geographic photographer ditches website, turns to the iPad. British Journal of Photography, https://petapixel.com/2011/09/22/nationalgeographic-photographer-ditches-website-in-favorof-ipad-app/ (accessed 02 October 2011)

[5] Argenti P. and Forman, J. The Power of Corporate Communication Crafting the Voice and Image of Your Business. IEEE Transaction on Professional Communication, Volume 46, no.2, (2003), pp. 149151.

[6] Bell, S.J. Image and consumer attraction to intraurban retail areas An environmental psychology approach. Journal of Retailing and Consumer Services, Volume 6, no.2, (1999), pp. 67-78.

[7] Benosman R. and Kang, S.B. Panoramic Vision Sensors, Theory, and Applications. Springer, (2001).

[8] Chen, E. QuickTime VR - an image-based approach to virtual environment navigation. SIGGRAPH '95, (1995).

[9] Cravens, K.S. and Oliver, E.G. Employees The key link to corporate reputation management. Business Horizons, Volume 49, no. 4, (2006), pp. 293-302.

[10]Edmonds, A. The art of interaction. Digital Creativity, Volume 21, no. 4, (2010), pp. 257-264.

[11]Felinto, D. Zang A.R. and Velho, L. Production Framework for Full Panoramic Scenes with Photorealistic Augmented Reality. XXXVIII Latin American Conference of Informatics (CLEI), (2012).

[12]Hong Kong Tourism Board. Phone and Tabled Apps. http://www.discoverhongkong.com/seasia/plan-your- trip/travel-kit/mobile-apps.jsp (accessed 21 February 2014)

[13]Hong S.Y. and Rim, H. The influence of customer use of corporate websites Corporate social responsibility, trust, and word-of-mouth communication. Public Relations Review, Volume 36, no. 4, (2011), pp. 389-391.

[14] Kim, J.U. Kim W.J. and Park, S.C. Consumer perceptions on web advertisements and motivation factors to purchase in the online shopping. Computers in Human Behavior, Volume 26, no. 5, (2010), pp. 1208-1222.

[15]Klein, S. Knowledge Visualization in Practice Challenges for Future Corporate Communication. Proceedings of the Ninth International Conference on Information Visualisation (IV'05), (2005).

[16] Langlotz, T. Degendorfer, C. Mulloni, A. Schall, G. Reitmayr G. and Schmalstieg, D. Robust detection and tracking of annotations for outdoor augmented reality browsing. Computers \& Graphics, Volume 35, no. 4, (2011), pp. 831-840.

[17]Lee R. and Lockshin, L. Halo effects of tourists' destination image on domestic product perceptions. Australasian Marketing Journal, Volume, 19, no. 1, (2011), pp. 7-13.

[18] McGloughlin, S. Multimedia Concepts and Practice. United States of America Prentice Hall, (2001).

[19] Moore, N. How to Do Research. 2nd edition, Library Association, (1987).

[20] National Geographic Traveller. 50 Places. iPad Appbased Publication, (2011).

[21] Pettigrew J.E. and Reber B.H. Journalists' opinions and attitudes about dialogic components of corporate websites. Public Relations Review, Volume 37, no. 4, (2011), pp. 422-424.

[22] Pitt, L.F. Parent, M. Steyn, P.G. Berthon P. and Money, A. The Social Media Release as a Corporate Communication Tool for Bloggers. IEEE Transaction on Professional Communication, Volume 54, no. 2, (2011), pp. 122-132.

[23] Pomering A. and Johnson, L.W. Constructing a corporate social responsibility reputation using corporate image advertising. Australasian Marketing Journal, Volume 17, no. 2, (2009), pp. 106-114.

[24] Ravine, M. Mars rover camera project manager explains 2MP camera choice. https://www.dpreview.com/articles/0353350380/curi osity-interview-with-malin-space-science-systemsmike-ravine (accessed 11 August 2012)

[25]Richard, M.O. Modeling the impact of internet atmospherics on surfer behavior. Journal of Business Research, Volume 58, no. 12, (2005), pp. 1632-1642.

[26] Stake, R. The Art of Case Research. Sage Publications, Thousand Oaks, (1995).

[27] Sunway. Sunway Hotel Resort \& Spa. https://www.sunwayhotels.com/sunwayresorthotelsp a/ (accessed 03 March 2012)

[28] Taketomi, T. Sato T. and Yokoya, N. Real-time and accurate extrinsic camera parameter estimation using feature landmark database for augmented reality. 
Computers \& Graphics, Volume 35, no. 4, (2011), pp. 768-777.

[29]Zonabend, F. The monograph in European ethnology. Current Socialogy, Volume 40, no. 1, (1992), pp. 49-60.

[30] Verhagen T. and Dolen, W.V. Online purchase intentions A multi-channel store image perspective. Information \& Management, Volume 46, no. 2, (2009), pp. 77-82.

[31]Wright, D.K. The role of corporate public relations executives in the future of employee communications. Public Relations Review, Volume 21, no. 3, (1995), pp. 181-198.

[32] J.P. Womack and D.T. Jones, "Lean Thinking," The Bath Press, Bath, UK, 1996.

[33] Yin, R. Case Study Research Design and Methods. 2nd edition. Sage Publication, Beverly Hills, (1994).

[34] Tellis, W. Introduction to Case Study," The Qualitative Report, Volume. 3, no. 2 [Online]. http://www.nova.edu/ssss/QR/QR3-2/tellis1.html (accessed 01 April 2017). 